\title{
INFRASTRUCTURE Carbovigilance: curtailing the global pharmaceutical carbon footprint
}

\author{
Authors: Avik Ray, ${ }^{A}$ Swati Sharma ${ }^{A}$ and Balakrishnan Sadasivam ${ }^{B}$
}

\section{Cutting emissions from the pharmaceutical industry is essential to curtailing the carbon footprint of healthcare globally. It is high time that the industry owned up to its carbon emission and took measures to curb back. In this study, we show how many of the leading global pharmaceutical firms have been able to reduce their carbon footprint while being profitable, indicating that modifications to reduce emissions would not pose a financial burden. We have come up with a 'modified emission intensity' index and a new term 'carbovigilance' in an attempt to bring this aspect of the pharmaceutical companies to light, while also encouraging them to work towards making positive contributions to a greener and healthier earth.}

KEYWORDS: carbon footprint, pharmaceutical industry, emission intensity, emissions reduction, greenhouse gas emissions

DOI: 10.7861/fhj.2021-0071

\section{Introduction}

While the focus of emission reduction has mainly been on the industrial sectors such as energy and automotive industries, the carbon footprint of the pharmaceutical sectors has not been given enough importance traditionally. This is evident from the dearth of published literature on pharmaceutical carbon emissions. In a paper published in 2009, the 2007 carbon footprint of the healthcare sector in the USA was estimated to be 546 million metric tonnes of $\mathrm{CO}_{2}$ equivalent $\left(\mathrm{Mt}-\mathrm{CO}_{2} \mathrm{e}\right)$ with hospitals and prescription drug sectors being the largest contributors. ${ }^{1}$ Another paper published in 2018 talked about carbon emissions of the global pharmaceutical sectors by including some of the major players in the industry. ${ }^{2}$ It highlighted that the emissions of the pharmaceutical industry were significantly more than the automotive industry. A detailed study carried out by the Sustainable Development Commission of the UK's NHS showed that the total carbon emission of the healthcare sector to

Authors: ${ }^{\text {A }}$ resident doctor, All India Institute of Medical Sciences

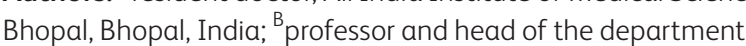
of pharmacology, All India Institute of Medical Sciences Bhopal, Bhopal, India be 32 million Mt- $\mathrm{CO}_{2}$ e in 2012, which was $38 \%$ of the public sector carbon footprint in England. ${ }^{3}$ The contribution of the pharmaceutical sector was $16.25 \%$. All of these point toward the fact that the pharmaceutical industry is responsible for a significant portion of carbon emissions, leading to environmental damage globally. There is a need to intervene quickly and find out ways to put a curb on the rising greenhouse gas levels in the atmosphere

\section{Methods}

We examined the carbon emission and financial data of the 12 largest pharmaceutical companies for 2 years (2017 and 2018), the time period for which we could obtain reliable data for all of these firms. The companies that we have selected for analysis have reported their carbon emissions consistently for these 2 years: Abbott, AbbVie, AstraZeneca, Bayer, Bristol Myers Squibb (BMS), Eli Lilly, GlaxoSmithKline (GSK), Merck, Novartis, Pfizer, Roche and Sanofi. The data were obtained from the Carbon Disclosure Project (CDP) and the annual reports of the companies. ${ }^{4}$ The financial data were cross-checked using Google Finance. The aggregate revenue of these companies in 2017 summed up to USD 419,760 million, which is about $37 \%$ of the gross sector revenue in that year while the amount was USD 440,052 million that comes out to be $36.5 \%$ of the total sector revenue.

\section{Results}

Fig 1 shows the emission intensities for these companies in 2017 and 2018. These were obtained by dividing the total carbon emissions of a year in $\mathrm{Mt}-\mathrm{CO}_{2} \mathrm{e}$ with the total revenue earned by the firms in the particular year in millions of US dollars (\$M). There were minor to substantial reductions for most of these firms from 2017 to 2018, with Bayer leading the pack by showing a reduction of $13.3 \%$ (supplementary material S1).

We modified the emission intensity index slightly by replacing revenue with operating incomes of the firms (in millions of US dollars) for the respective years (dividing the total carbon emissions of a year $\left(\mathrm{Scope} 1+2\right.$ ) in metric tonnes of $\mathrm{CO}_{2}$ e with the operating income in a financial year). We have termed this as the 'modified emission intensity' and has got the same unit as that of emission intensity ie $\mathrm{Mt}-\mathrm{CO}_{2} \mathrm{e} / \$ \mathrm{M}$. Fig 2 shows the modified emission for the firms in both the years. In contrast to the emission intensity chart, a greater number of companies show increased modified emission intensities for 2018 as compared 


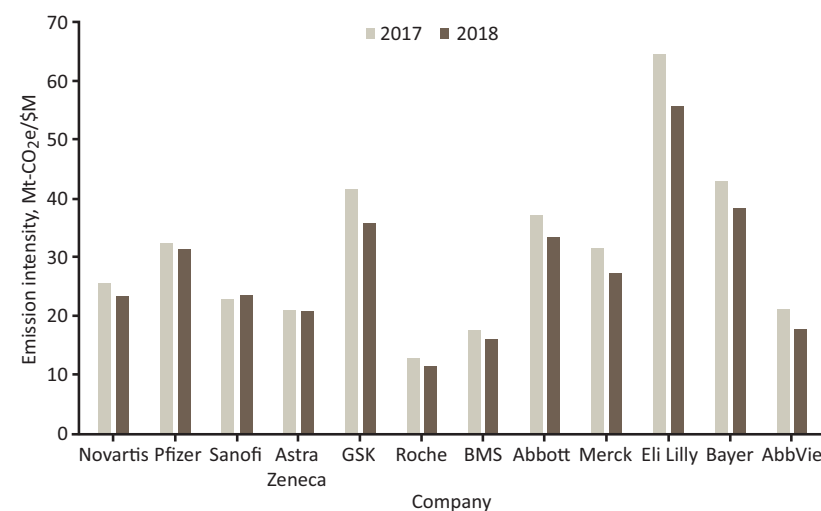

Fig 1. Emission intensities of pharmaceutical companies (by total revenue). BMS = Bristol Myers Squibb; GSK = GlaxoSmithKline.

with 2017, including Bayer, with Eli Lilly showing the maximum reduction.

Fig 3 is a combined chart showing percent changes in the operating incomes, sales revenue and carbon emissions. The maximum change in operating income was experienced by Eli Lilly followed by GSK, Abbott and Merck, with all of them showing emission reduction. On visually comparing the ratio of percent change of operating income upon carbon emission for Eli Lilly and GSK, the former clearly had a favourable profile (improvement in operating income with a concurrent decrease in the carbon emission). Interestingly, although Fig 1 shows that Bayer had the maximum reduction in the emission, it came at a cost of substantial reduction in its operating income as evident in Fig 3.

The Pearson's correlation coefficient ' $r$ ' between these two indices was 0.89 , depicting a strong positive correlation. Through validation and further refinement, this modified index could reliably be used for description of the carbon emissions of firms, with a focus on the operating income instead of sales revenue earned in a financial year. This would have managerial implications, helping the firms estimate the impact of curbing emissions on their net profit.

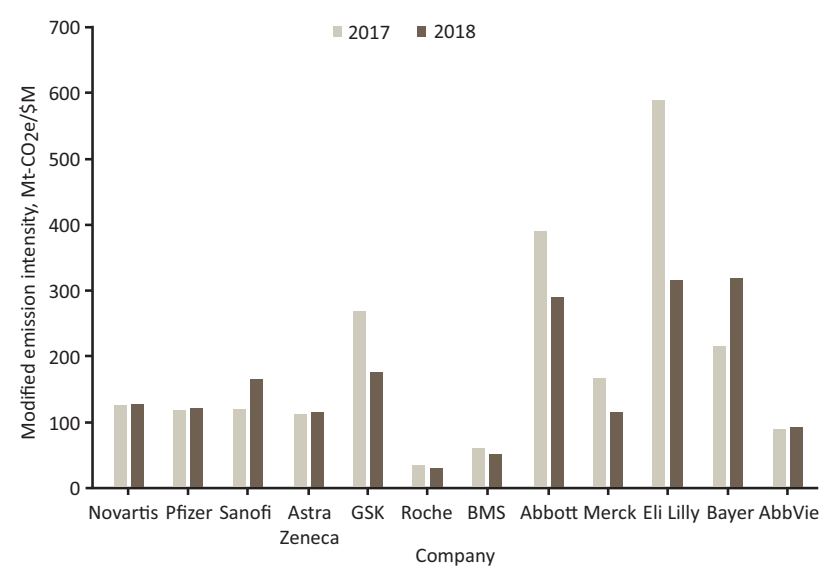

Fig 2. Emission intensities (modified) of pharmaceutical companies (by operating income). $\mathrm{BMS}=$ Bristol Myers Squibb; GSK = GlaxoSmithKline.

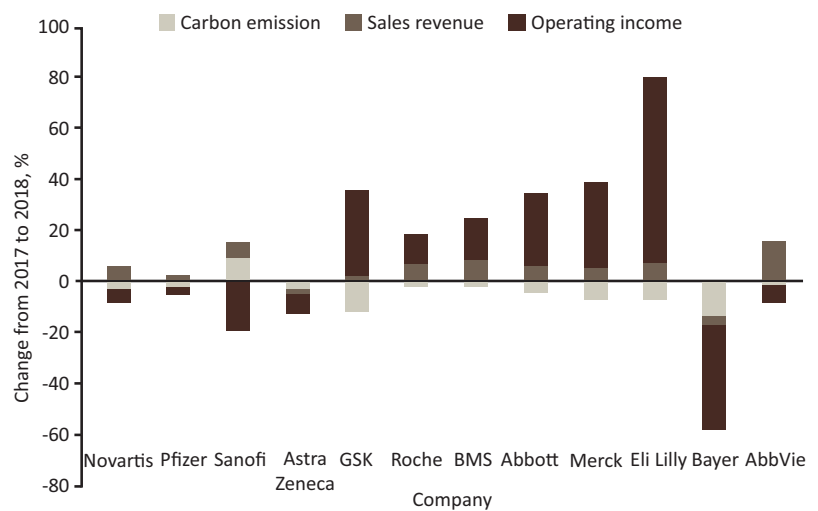

Fig 3. Changes in carbon emission, sales revenue and operating income of pharmaceutical companies. The compound bars help understand the relative magnitude of change in different components for each of these companies. BMS = Bristol Myers Squibb; GSK = GlaxoSmithKline.

\section{Discussion}

Our findings suggest that most of the pharmaceutical firms have been able to successfully bring down their carbon emissions while having a substantial rise in both revenue earned and operating income. This indicates that bringing about changes in the processes to meet the emission standards have not impacted the sales and profits of the companies negatively. The proposed modified index shows that the investments done to reduce emissions have not been a financial burden for most of the leading global pharmaceutical establishments. This should encourage the firms, especially the major players in the industry, to formulate strict emission standards and adhere to those strategies. Another encouragement would be the upgrading of the company's reputation as well as the viable boost to the employees' morale by executing corporate social responsibility towards a greener environment and, thus, giving back to the cognate community. ${ }^{5}$ Through the reduction of carbon emissions (via means such as manufacturing process modification and refinement), global pharmaceutical firms would be able to add on to the contribution they are already making to the society by formulating life-saving medicines, enriching the sustainability of mankind even further.

\section{Conclusion}

The study findings illustrate that many of the leading global pharmaceutical firms have been able to reduce their carbon footprint while staying profitable, signifying that modifications to reduce carbon emissions would not pose a financial burden and that it would contribute positively to societal health in the long run. We take the liberty to coin the term 'carbovigilance' for creating systematic awareness about the expanding carbon footprint of the pharmaceutical industry and spreading the message of importance of curbing carbon emissions in this industry sector.

\section{Supplementary material}

Additional supplementary material may be found in the online version of this article at www.rcpjournals.org/fhj:

S1 - Further data on carbon emission, sales revenue and operating income of the pharmaceutical companies. 


\section{References}

1 Chung JW, Meltzer DO. Estimate of the carbon footprint of the US health care sector. JAMA 2009;302:1970-2.

2 Belkhir L, Elmeligi A. Carbon footprint of the global pharmaceutical industry and relative impact of its major players. J Clean Prod 2019;214:185-94.

3 NHS Sustainable Development Unit. NHS carbon footprint. NHS, 2012. www.sduhealth.org.uk/policy-strategy/reporting/nhs-carbonfootprint.aspx. [Accessed 14 April 2021]

4 Carbon Disclosure Project. www.cdp.net [Accessed 14 April 2021].
5 Leisinger KM. The corporate social responsibility of the pharmaceutical industry: idealism without illusion and realism without resignation. Bus Ethics Q 2005;15:577-94.

Address for correspondence: Dr Avik Ray, Department of Pharmacology, All India Institute of Medical Sciences Bhopal, 3rd Floor, Medical College, Saket Nagar, Bhopal 462020, Madhya Pradesh, India.

Email: avik.ray018@gmail.com

Twitter: @AvikRay3 